\title{
Estrategia y propaganda. Arquitectura militar en el Caribe (1689-1748)
}

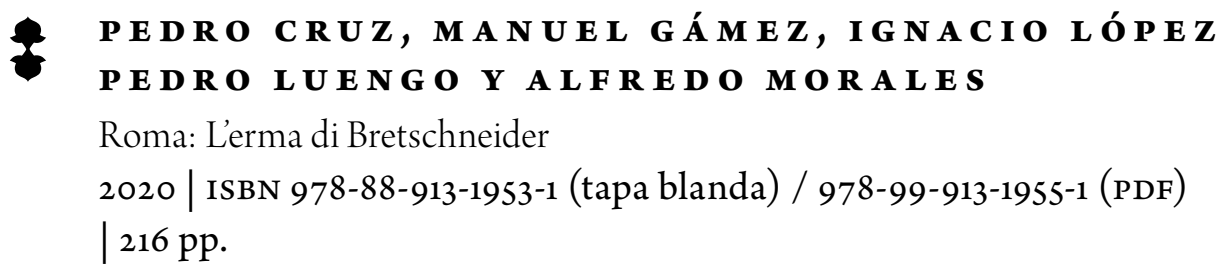

DOI: https://doi.org/I0.22380/20274688.2049

JORGE GALINDO-DÍAZ Universidad Nacional de Colombia, sede Manizales

$\mathrm{R}$

esultado de un extenso trabajo de pesquisa que llevó a cabo un equipo de jóvenes investigadores coordinado por Alfredo Morales, catedrático de la Universidad de Sevilla, este libro pone nuevamente el foco de interés sobre el vasto conjunto de obras de arquitectura militar diseñadas y construidas por algunos de los ejércitos europeos en las costas del Caribe americano y el golfo de México, en un periodo bien acotado de la historia universal (I689-I748), siguiendo las etapas de transformación de las escuelas de fortificación propuestas por Black.

Los objetivos del libro son claramente compartidos por el conjunto de autores. Por una parte, se pretende demostrar la manera en que cada potencia europea planteó un modelo propio de gestión del territorio a partir de modelos teóricos que perfilaron su aspecto, así como el de varias ciudades que crecieron acompañadas de estructuras defensivas; a ello corresponde lo relacionado con la estrategia, que bien anuncia el título. Por otra parte, se intenta unificar campos de trabajo que, de manera independiente, se han ocupado de las imágenes del poder en la arquitectura, complementando los enfoques de autores como Van Eck - centrado en la arquitectura europea, con el uso del lenguaje antiguo como punto de referencia—, Kagan — quien dirige su atención a las imágenes 
de poder presentes en las ciudades europeas a partir de piezas pictóricas- y Mínguez — cuyo análisis se hace a través de la fiesta y la iconografía regia-, que dan respuesta al aspecto propagandístico que bien se le puede atribuir al conjunto de fortificaciones estudiado.

Para atender el cumplimiento del primer objetivo, se exploran tanto las condiciones históricas generales que influyeron sobre la toma de decisiones militares en el área del Caribe durante las primeras décadas del siglo XviII, como el desarrollo del cuerpo conceptual que se fue forjando en torno a la idea de fortificación moderna, los que conjuntamente hicieron del Caribe el espacio geográfico en el cual se materializarían murallas y fortificaciones que hicieron parte de sistemas de defensa. El análisis de los ejemplos identificados, así como de los discursos teóricos, permite diferenciar dos miradas estratégicas contrapuestas: el modelo hispano, que intentaba ofrecer un sistema de protección regional a sus puertos y rutas comerciales; y el modelo compartido por otras potencias, más interesado por conformar centros de aprovisionamiento. A partir de esto, surgen entonces a la vista de los autores sendos modelos de gestión territorial: uno mucho más orientado a la ejecución de grandes obras de infraestructura militar, desarrollado por los ingenieros españoles, y el otro, caracterizado por pequeñas piezas fortificadas que demandaban un aparato burocrático más lento pero eficiente, a cargo de ingenieros franceses e ingleses.

Se trata de una mirada comparada, novedosa, ausente de buena parte de los trabajos previos orientados al estudio de las fortificaciones americanas, en su mayoría lastrados por visiones nacionalistas, o en ocasiones limitados a entender la manera en que ellas fueron el reflejo literal o la adaptación inteligente de los sistemas construidos en las naciones europeas. Sin embargo, las conclusiones de la primera parte de este libro no logran demostrar con precisión otras afirmaciones, como aquella referente a la existencia de un mayor diálogo técnico entre los ingenieros españoles y las poblaciones locales, muy a pesar de que su modelo administrativo también estuvo fuertemente concentrado en instituciones peninsulares, como bien lo han demostrado otras investigaciones precedentes. Si bien en el libro se hace una descripción de los principios que guiaban el uso de materiales de construcción en Europa y América, los aspectos propios de las técnicas constructivas y los procesos de administración y control de las obras no están suficientemente documentados como para soportar lo anterior.

La segunda parte del libro aborda de lleno la descripción y el análisis de recintos, bahías y penínsulas, incorporando también un tema poco estudiado, como lo ha sido el de la fortificación de campaña. El espacio de análisis parece 
expandirse con la inclusión de casos muy poco estudiados por la historiografía dedicada al tema: por ejemplo, al abordar las islas fortificadas, se incluyen el fuerte de S. Charles en la isla francesa de Guadalupe, el fuerte Condé, levantado por los franceses a orillas del río Mobile en Luisiana, o el de San Felipe de Bacalar en la península de Yucatán. De tal manera, lo histórico contextualiza lo tipológico, valiéndose de las imágenes de las plantas originales en casi todos los casos, para así dejar en evidencia la manera en que el patrón geométrico se fue adaptando a las condiciones de cada territorio y en que el trazado urbano se subordinó al carácter defensivo de las murallas.

En la parte final de este trabajo se incluye una mirada a la estructura organizacional de los ingenieros en América que recuerda los trabajos ya clásicos de Capel et al. y Gutiérrez y Esteras, con un apartado sobre el papel que tuvo Félix Prósperi, ingeniero militar italiano que, al servicio de la Corona española, publicó en México el que bien puede considerarse el primer tratado de fortificación impreso en América, en el que introdujo notables aportes a los sistemas de fortificación existentes, en atención a los problemas presupuestales que conllevaba su aplicación en el Nuevo Mundo.

Las conclusiones de la segunda parte no logran, sin embargo, asociar de una manera clara la idea de propaganda con la mera traza de los proyectos de fortificación. Además de las portadas edificadas sobre los lienzos de las murallas, la imagen del poderío imperial bien podría entenderse como algo que supera lo iconográfico y abarca la fuerza tectónica de las obras construidas, el dominio sobre la naturaleza y la fuerza del mar, la durabilidad de los materiales y el dominio de la geometría como herramienta de control sobre el entorno. Tal vez por esto, las conclusiones finales bien retoman aquellas formuladas al término de la primera parte. De tal manera, se reitera que, en efecto, el libro demuestra la existencia de varios modelos imperiales de entender y controlar el territorio caribeño, para superar la idea de una forma única, americana y colonial, y descartar casi de plano la reivindicativa tesis de Zapatero, que tantos adeptos ha tenido, acerca de una escuela de fortificación autóctona.

En relación con las obras de fortificación construidas en el territorio de lo que hoy es Colombia, el caso de Cartagena de Indias ocupa toda la atención y el interés de los autores, quienes demuestran un conocimiento del arco histórico que en materia de fortificaciones vivió la ciudad y sientan las bases para investigaciones que es necesario llevar a cabo, como aquella que haga precisión sobre la primera academia de matemáticas que allí se habría instalado, bajo la dirección del ingeniero militar Juan de Herrera Sotomayor. Limitaciones de 
espacio y tiempo seguramente impidieron dedicar una mirada a otras fortificaciones diseñadas o construidas en el Caribe colombiano, muy poco conocidas, desde los bosques tropicales del Darién hasta las tierras secas de La Guajira.

Con destacable rigurosidad histórica, el libro incluye valioso material gráfico, representado tanto en fotografías de sus autores como en mapas y planos. Lo primero revela la existencia de un trabajo de campo necesario en la comprensión de la realidad construida; lo segundo, un trabajo de búsqueda documental en importantes archivos de Europa y América. Todo ello refuerza la amplia base bibliográfica que comprende la casi totalidad de estudios recientes sobre el tema y, de manera especial, la tratadística clásica consagrada al arte militar. Si bien, las conclusiones pueden quedarse cortas frente a tantas capas de análisis, este libro constituye un valioso aporte a la historiografía de la ocupación del territorio americano, así como a la de las técnicas constructivas en un momento decisivo en las relaciones entre Europa y América.

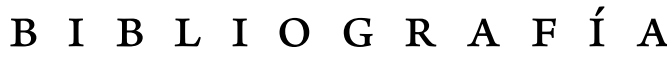

Black, Jeremy. European Warfare in a Global Context, I660-I8I5. Londres y Nueva York: Taylor \& Francis, 2007.

Capel, Horacio, Omar Moncada y Joan Sánchez. De Palas a Minerva. La formación y la estructura institucional de los ingenieros militares en el siglo XVIII. Barcelona: Consejo Superior de Investigaciones Científicas, 1988.

Gutiérrez, Ramón y Cristina Esteras. Territorio y fortificación: Vauban, Fernández de Medrano, Ignacio Sala y Félix Prósperi: influencia en España y América. Madrid: Tuero, I991.

Kagan, Richard. Urban Images of the Hispanic World. 1493-I793. New Haven: Yale University Press, 2000.

Van Eck, Caroline. Classical Rhetoric and the Visual Arts in Early Modern Europe. Cambridge: Cambridge University Press, 2007.

Zapatero, Juan Manuel. "La escuela de fortificación hispanoamericana". Actas del XXXVI Congreso Internacional de Americanistas. Sevilla: Ecesa, 1966, pp. 6I-69. 